\title{
Chapter 1: Introduction
}

\section{Introduction}

As the focus of interest in Information Literacy spreads from the university out into the world of work, can librarians and theoreticians be confident that they can continue to apply existing understandings and definitions? Both anecdotal and research evidence suggests not; that Information Literacy may not manifest as the same phenomenon in the workplace as it does in the academic environment. Young professionals, confronted by a way of dealing with information quite different to the academic, may be disorientated by the experience (Osborn 2011) and find themselves having to think about their relations to information in new ways: in terms of meaning, value, and purpose.

How is Information Literacy to be reconceptualised for the workplace? Through what recasting of its parameters are librarians and library managers to better understand and so effectively support workplace professionals, and the students studying for those professions, in their information needs and use? How can their Information Literacy be developed in a way that is meaningful and appropriate for them? Perhaps the question is one of evidence as much as conception: how can professions, many of which are especially focused on, and dependent on, information (Evetts, 2006) be supported if librarians lack evidence as to how and why they use that information? Do we know in what way Information experiences in the workplace are significant to professionals themselves, their employers and educators and society at large? Indeed, what is the 'workplace' in an increasingly virtual information world? 
There are many ways in which Information Literacy appears to have a crucial role in professional and workplace performance. Some recent research in the UK, Australia, Hong Kong and the United States has looked at these roles from new and developing perspectives. This book describes several facets of Information Literacy's role in the contemporary information driven workplace, including its role in assuring competent practice, its value to employers as a return on investment, and its function as an ethical safeguard in the duty and responsibilities professionals have to clients, students and employers. It also focuses on new methods for developing Information Literacy in professional groups, describing in detail methods for formulating evidence-based Information Literacy educational interventions, and the development of systems which facilitate learning in the workplace. All of this should be of value to librarians and library managers as they attempt to survey the wide and complex workplace information horizon.

One of this book's principal aims, addressed in several chapters, is to help librarians, library managers and Information Science students understand how Information Literacy is experienced by those professions they support and facilitate. The answer to the question of how Information Literacy is experienced addresses the knowledge 'gap' addressed above: how can library professionals know how information is used in the workplace? Such knowledge, potentially acquirable through appropriate research, shows how librarians can more profoundly engage with workplace professionals by, amongst other things, more precisely focus their information resource provision, as well as develop programmes of Information Literacy education tailored to each specific profession. 
The book also attempts to assist the wider world of professional workers and their employers and educators to grasp the nature and value of Information Literacy as a key workplace attribute; something still rare. Hopefully the book will help promote awareness of its role in best practice and evidence-based practice, and its value in ethical practice in those professions, encouraging educators to integrate Information Literacy education into their courses, and showing in what contexts this might be achieved. Overall, we hope the book is successful in promoting the idea that to be an effective and cost-effective professional requires Information Literacy, and in addition, showing where and in what way such attributes promote effective workplace practice.

This introduction gives a brief overview of some key issues, problems and ideas discussed in each chapter. There is a wide range of perspectives, both international and UK-based, from authors often with an extensive history of thinking and writing about Information Literacy; research methodology, research findings, and organisational and individual perspectives are all discussed and put into context. As a result, styles of writing vary, but we have at all times tried to avoid too great a level of abstraction, though in some contexts abstraction is necessary (and hopefully illuminating!).

\section{Setting the Scene}

In Chapter 2, Professor Annemaree Lloyd, a recognised international authority in Information Literacy and the workplace, provides an overall context and background to the issues discussed in the book. She discusses how the intensification of work 
and creation of new ways of working can present librarians with challenges in terms of creating Information Literacy education that provides scaffolding for students' transitions into professional or vocational practice. Librarians must recast their teaching practices to accommodate changes in the nature of work.

In Chapter 3, the editor of this volume, Dr Marc Forster, discusses how Information Literacy workplace experience has been, and could be, determined. He begins by looking at ways in which researchers have sought to understand the role of Information Literacy in the workplace and elsewhere. Looking at Information Literacy as a phenomenon to be experienced, by asking the question 'what does Information Literacy mean to the worker' is one way that promises to help solve the knowledge gap librarians experience when considering the workplace information world. By looking at how Information Literacy is understood in varying ways within the differing employee roles within a workplace, librarians and other researchers are able to uncover, in a particularly detailed way, how Information Literacy develops a professional's knowledge: the knowledge they need to perform their different roles. In fact, as Christine Bruce and colleagues have described, it is a key component of learning (Bruce and Hughes 2010). Indeed, some researchers have come to the conclusion that Information Literacy experience always varies depending on context, and is always focused on developing the knowledge needed in that particular context. In the workplace, this implies Information Literacy allows a health, legal or business professional to work from an adequate basis of knowledge so that the patient, client or customer receives a fully competent and effective service in each of the many contexts such professionals operate. 
Several chapters in this book are based to a greater or lesser extent on this 'relational' way of approaching Information Literacy; one that recognises that it is experienced in different ways, depending on the differing contexts of workplace activity and the varying roles of the professional worker.

\section{A Relational Approach to Information Literacy}

In Chapter 8, Professors Mary M. Somerville and Christine Bruce give a vivid example of an application of the relational approach and information-knowledgelearning paradigm in the context of the workplace. They illustrate how a workplace can be transformed for the better by using Information Literacy to inform its structures and relationships: an approach which has been given the name 'Informed Systems'. This approach aims to develop ways to facilitate continuous communication, decision making, action taking, and interactive evaluation processes through 'informed learning' experiences that catalyse and sustain relationships within the workplace that facilitate continuous enquiry and improvement. Through collaborative design, co-workers manage the flow of information to enable the organisation to develop the knowledge it needs to flourish amidst dynamically changing circumstances. The leadership role is to foster purposeful inquiry relationships to create local information experiences that further conditions for learning that have the potential to transform the organization as a whole. Informed Systems advances collaborative evidence-based decision-making, a key feature which will come to the fore frequently within the chapter as expressed through mutual team information exchange experiences. When framed as Information Literate exchanges within a workplace, these experiences can, and do, transform 
processes for intuiting, interpreting, integrating, and institutionalizing knowledge. Leaders and managers will find particular value in this chapter about workplace revitalization.

While the research and development for 'Informed Systems' occurred in North American academic libraries, the principles of collaborative and systemic Information Literacy are transferable to other contemporary workplace settings. This chapter offers readers an enlightening example to understand how Information Literacy can inform structures, processes, and practices within a workplace. This remarkable initiative illustrates that it is possible for organisations to take responsibility for creating their futures.

In Chapter 6 Dr Marc Forster uses the relational approach and informationknowledge-learning paradigm to look at Information Literacy as a 'personal' attribute. Information Literacy experience of different levels of complexity reflects different breadths of professional 'horizon': helping the individual perform appropriate professional roles of whatever level of responsibility, while simultaneously, and in a related manner, facilitating relationships and helping teams to function, whether as a collaborator, teacher or leader. As other chapters in this book emphasise, Information Literacy in the workplace has a prominent collaborative dimension. A dimension that allows the individual, operating in different roles, at different levels of complexity of Information Literacy experience, to contribute to a team or wider organisation's knowledge aims and needs, or to work with clients or patients in a mutually beneficial exchange of information. 


\section{The Information Literate Workplace}

Several of the chapters in this book attempt to take the perspective of the workplace itself rather than that of individual experience. What is the workplace in an increasingly virtual information world?

In Chapter 4, Dr. Elham Sayyad Abdi looks at the changes that integration of digital tools into workspaces may cause in understanding Information Literacy. In professions in which virtuality is an unavoidable component, Information Literacy can be experienced as a combination of physical and virtual workplace. The latter's key characteristics include an enhanced professional network. The chapter reviews the role of virtuality in workplace Information Literacy experience. It considers how virtuality, as an element of work context, enables Information Literacy to be experienced in a multidimensional and professionally enhanced way, perhaps suggesting a new theoretical construct for Information Literacy in the modern professions.

In Chapter 5 Stéphane Goldstein and Dr. Andrew Whitworth ask the questions: How is Information Literacy valued in the workplace? What are the concrete benefits enterprises derive from recruiting, retaining and developing individuals who are information literate? What returns on investment might be achieved in areas like providing information skills training to employees, developing new information handling procedures, or even reconfiguring an office and going 'paperless'? What does the Information Literacy of employees, at all levels, add to the performance of enterprises? Their chapter draws on a funded project that sought to identify how Information Literacy contributes to a range of indicators of value for enterprises in the commercial, public and not-for-profit sectors, including organisational improvement, 
productivity, accountability and flexible or agile working. These indicators are mapped against five broad areas where enterprises make investments that relate to the use and handling of information and data. The chapter describes how the resulting correlation provides an analytical framework - which the project expressed through a practical tool - that enables enterprises to recognise how Information Literacy contributes to their corporate health.

In Chapter 10, Dr Bonnie Cheuk asks: If Information Literacy is important in the digital world, why don't we see the phrase appearing in job descriptions, or listed as essential skills similar to communication skills; time management or project management? Dr Cheuk posits that "Information Literacy" is of value to any information-driven company and can often be found there. However it is hidden within the contexts of business functionality; it is so embedded in the business activities that one cannot talk about it separately.

Dr Cheuk suggests that Information Literacy models borrowed from the academic context are unlikely to meet the changing definition of information and the dynamic information needs of knowledge workers in different business context. A refined definition of Information Literacy in the workplace is put forward.

\section{Best Practice and Information Literacy's Ethical Role}

In Chapter 7, Dr Marc Forster turns his attention to how Information Literacy contributes to professional norms of competence, effectiveness and fulfilment of the ethical necessity to achieve the best possible level of practice. To be an effective lawyer, doctor, nurse, social worker, or to work in the financial sector, is to deal each 
day with information. One must know when research evidence or other relevant legal, business, personal or other information is required, how to find it, how to critique it and how to integrate it into one's knowledge base. To fail to do so may result in defective practice. It follows that in some contexts to be Information Illiterate qualifies as unethical practice, as failure to do everything necessary to operate from a complete knowledge base could have devastating consequences for clients or employers. In fact there seems to be an ethical requirement to go beyond this to achieve the best practice possible, in order to achieve the best outcome possible for the patient or client. This requirement demands highly focused and complex information searching, assessment and critiquing skills.

If Information Literacy is worth investing in by employers, allowing employees to adapt to changing information environments and so develop personally (including the ability to function in a team), it must be shown to have a key role in the achievement of 'Best Practice', the most effective and efficient performance possible. In fact it appears from several research studies to have a role in the philosophic underpinning and practical processes of 'Evidence-based Practice', a form of Best Practice which explicitly focuses on the value of information in the form of complete, appropriate and contextualised research evidence. Research suggests Information Literacy is a key tool in maintaining effective and competent practice and is a fundamental aspect of evidence-based healthcare. To be information literate allows professionals to be aware of and able to locate, correctly interpret and apply research in a full and complete manner, in a way that promises to achieve the best outcome for their patient or client. Evidence might be in the form of primary sources such as papers discussing individual research studies, or secondary sources such as professional guidelines and systematic reviews of research. 
This is a new way of looking at Information Literacy, and one vital to the understanding of its role in professional practice. This new understanding would also imply that the acquisition of Information Literacy competencies has an ethical necessity. Does Information Literacy education emphasise this? The literature suggests not. Could it, however, be the means of driving forward Information Literacy education in the professions?

\section{The Development and Promotion of Information Literacy}

What of the educational, developmental perspective? Is Information Literacy valued in the workplace to the extent that its development is valued? How might librarians and professional trainees and educators develop the information skills required in professional life?

In Chapter 10 Dr Bonnie Cheuk explores knowledge workers, in different roles, functions and levels, who work under different operating models and company culture. She asks if and when Information Literacy adds value to the business, and if it does, how can information professionals play a business-driven, strategic yet pragmatic role to enhance knowledge workers Information Literacy capabilities. Despite the lack of acknowledgement and understanding of Information Literacy in the work world, many different roles within the workplace turn out to be information focused. Information professionals can be more broadly defined as key employees of whatever label who have to consciously consider how best to help the company leverage information and/or create information systems, service and marketplace to create value for employers, clients or business stakeholders. 
A practical case study is put forward to illustrate how a global company might successfully roll out an Information Literacy program disguised as a "change management" program within a broader culture-change initiative.

In Chapter 9, with a related focus, Dr Stephen Roberts explores the ways in which higher orders of information professional competence can be introduced into programmes of higher education teaching and learning, with a view to deeper and wider dissemination across occupations and domains within the workplace, and to see these competences embedded in organizational learning and personal development.

The term 'information professional' (IP) has come to provide an umbrella expression to denote the recognized educational and occupational focus for the qualified librarian, information manager, information services provider, knowledge manager, and for those who work in the fields of documentation, records and archives. It has become a term to reflect the rise of an information intensive society and the knowledge economy based not just on ICT and digital platforms but on wider social, behavioural and organizational changes with which these are linked. With a professional group so defined there is not only an aspiration to engender a wider dispersion of higher order professional competences in information and knowledge work but a real possibility to propagate such roles and capacities more widely across other occupations and social groups in the workplace.

Dr Roberts revisits an initiative undertaken during the development an MSc in Corporate Communication. An opportunity was identified in this information and communication rich discipline for information professional academics to make an innovative contribution. A module was developed: 'Presenting Information 
Intelligence and Knowledge' (PIIK) to provide a focus for introducing an information professional contribution to curriculum and learning (Roberts, 2002; 2004). The module may suggest a model for developing information professional competences in disciplinary domains.

There have been several attempts in recent years to put forward an evidence-based, 'relational' form of Information Literacy education, made possible through the use of research techniques investigating the range of Information Literacy experiences known to apply to a particular group, such as students or academics. This has now been taken further through the development of the 'Experience Framework', discussed by Dr Marc Forster in Chapter 11: a framework formed from a more detailed range of contexts and levels of complexity of workplace experience of Information Literacy in the relevant group or profession; detail made possible through more structured data analysis techniques. Groupings of aspects of that experience are used to formulate, through the application of Variation Theory, an education theory developed from previous research, learning contexts and aims which can form the basis of highly focused and detailed educational interventions. Such evidence-based methods have the highest probability of developing Information Literacy, but also of reinforcing its perceived relevance for professionals and their employers, based as they are on actual workplace experiences.

One of the recurrent problems in Information Literacy education is how 'progress' can be assessed and monitored meaningfully. Are the skills or knowledge domains that are usually assessed the key ones? A new experience-based means of monitoring the growth of Information Literacy has been developed in the context of the research described above. The method can be applied to any group or 
profession, but is especially useful in the wide ranging and complex information world of the workplace.

The workplace is a context in which approaches to Information Literacy beyond the well-established academic or library focused are needed. We hope that you find the theories and research evidence discussed in the following chapters thought provoking and seminal. Research provides a source of new ways of looking at Information Literacy and its development. Perhaps this book will stimulate you to formulate your own research ideas. 